\title{
The big one: The epistemic system break in scholarly monograph publishing
}

(c) The Author(s) 2012

Reprints and permission: sagepub.co.uk/journalsPermissions.nav DOI: $\mid 0.1$ | 177/|46|4448|2465|43 nms.sagepub.com

@SAGE

\section{Phil Pochoda'}

University of Michigan, USA

\begin{abstract}
A system of scholarly monograph publishing, primarily under the auspices of university presses, coalesced only 50 years ago as part of the final stage of the professionalization of US institutions of higher education. The resulting analogue publishing system supplied the authorized print monographs that academic institutions newly required for faculty tenure and promotion. That publishing system - as each of its components - was bounded, stable, identifiable, well ordered, and well policed. As successive financial shocks battered both the country in general and scholarly publishing in particular, just a decade after its final formation, the analogue system went into extended decline. Finally, it is now giving way to a digital scholarly publishing system whose configuration and components are still obscure and in flux, but whose epistemological bases differ from the analogue system in almost all important respects: it will be relatively unbounded and stochastic, composed of units that are inherently amorphous and shape shifting, and marked by contested authorization of diverse content. This digitally driven, epistemic system shift in scholarly publishing may well be an extended work in progress, since the doomed analogue system is still fiscally dominant with respect to monographs, and the nascent digital system has not yet coalesced around a multitude of emerging digital affordances.
\end{abstract}

\section{Keywords}

Analogue publishing system, digital publishing system, accreditation, authorization, epistemic break, digital soup, digital shrew, stochastic 


\section{Darnton's publishing circuit}

In a much-cited article 'What is the History of Books' (Darnton, 1982/2009: 175-206), Robert Darnton utilized the actual developments and participants in the 1770 publication of Voltaire's nine-volume Questions sur l'Encyclopedie to generate a schematic model of the full publication circuit, the flows of materials and ideas from author to reader (with intermediate stops at publisher, printer, shippers, and booksellers). Darnton claims, with much justification, that this model of the 'entire communication process' should apply 'with minor adjustments to all periods in the history of the printed book' (Darnton, 1982/2009: 180).

Darnton illustrates the communications circuit with the diagram shown in Figure 1 (Darnton, 1982/2009: 182).

Darnton's 'publishing model' or 'publishing circuit' can also be considered a publishing 'system,' since it delineates a set of components that interact with each other in regular and ongoing ways, and whose overall behavior or output could not be predicted or explained by any or all of the components separated from the others. Any system is an arbitrary slice through, or selection from, a much broader potential array of interacting elements. The value of the system model consists of its ability to reveal and/or to explain regularities in important or recurrent empirical phenomena. In the case of Darnton's model, the claim that it incorporates and helps conceptually organize and interpret the primary activities connected with print publishing over the course of two centuries underwrites its claim to significance.

Since each of the elements of the publishing system is itself a system, and can be decomposed into its own interacting components, the publishing system can be viewed as constituted of linked subsystems. For example, the publisher is represented in Darnton's general publishing model (although not in his nuanced narrative account of the actual publication of Voltaire's work) as a monolithic entity - a 'black box' that receives inputs from the author and sends outputs to the printer. However, for other analytic or practical purposes, publishers must themselves be treated as a system, composed of, or deconstructed into, interacting components (or subsystems), such as editorial, production, marketing, sales, and business departments.

Conversely, the publishing system can be considered itself as a subsystem of larger economic, political, or cultural systems: that is, a more generalized, more encompassing, societal system model could be constructed in which the publishing system is treated as a single component. Darnton takes account of the substantial impact of the tumultuous economic, political, and cultural environments of pre-Revolutionary Europe upon the publication of Voltaire's work by treating them as boundary conditions that significantly affect and are, in turn, affected by the publishing circuit. In technical terms, the publishing system is an open system, exchanging inputs and outputs with elements or systems outside itself (Patten and Auble, 1981: 897). Open systems may encounter certain boundary conditions - the environmental states that feed into the system - that facilitate system stability over a wide range of internal activity, while other boundary conditions make system stability difficult or even impossible. In a system subject to mathematical formulation, the latter outcome means that there are no system solutions for certain values or a range of boundary conditions. In the example of 


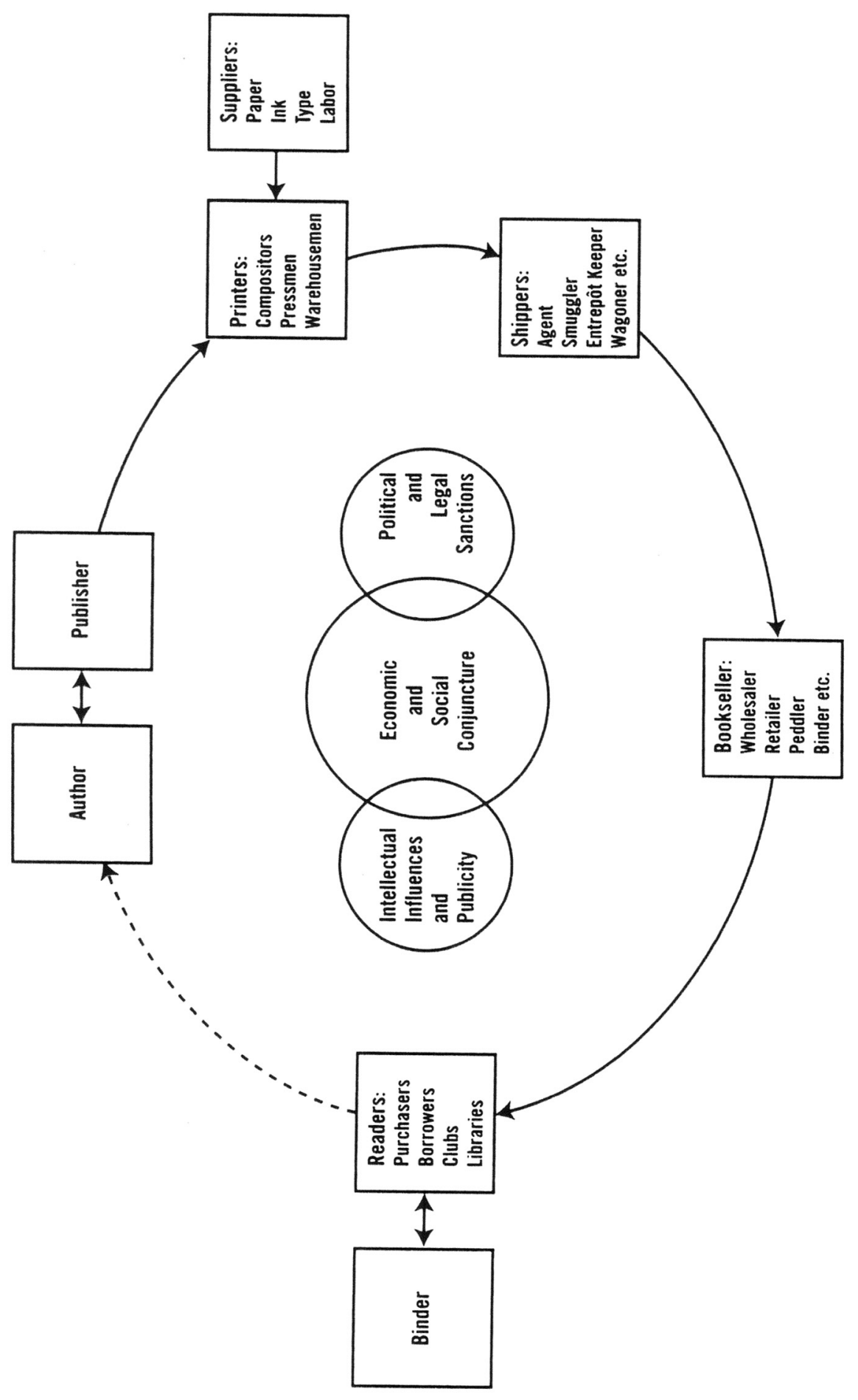

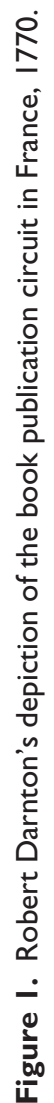


the publishing system, particular economic conditions (e.g. extreme general financial instability or crises, or specific economic developments in the publishing sector) or political conditions (e.g. rigid censorship by French royal agents) can and did interrupt the publishing system (at least as regards Voltaire's book) for shorter or longer periods of time.

\section{Coalescence of the scholarly print publishing system: professionalization, authorization, and accreditation}

Until the 1960s, the circuit of monograph scholarly publishing - which at that time included approximately 40 university presses (Givler, 2002) - could be depicted in a diagram that much resembled Darnton's schematic of the 18th century publishing circuit. Authors, generally faculty and graduate students at the same institution as the press, would hand over their manuscripts to the press; the press would ready them for production and deliver the edited manuscripts to a printer; the printed books would continue on through a distributor, bookstore or library, to readers. What were missing were strong and consistent controls on the quality of the output, the books produced and circulated. That is, it lacked feedback from the core output - the quality not of the physical product, the container, but of the argument, the content. To qualify as a cybernetic scholarly system, content quality needed to be sampled, assessed, and then fed back into the publishing process as a control mechanism that effects changes at the book level: the system must display strong and persistent feedback loops that produce a reliable threshold of content quality (Wiener, 1948 and 1961: 95-115).

In the 1960 s the scholarly publishing circuit installed such feedback, in the form of professional disciplinary standards, within the publishing system at multiple locations. University presses, long the center of scholarly publishing, now organized and implemented such feedback by submitting every monograph to an external review process that was adapted, with some variations, from similar systems employed for scholarly journals. While the scholarly disciplines had previously weighed in formally but erratically post-publication on the merits of monographs through reviews in prestigious professional journals, and informally in many other ways, by building in the review hurdle or authorization within the publishing process itself, presses attempted to ensure that every published monograph and all published content, attained at least a minimal professional level.

Not coincidentally, the professionalization of press content was influenced by and, in turn, played a significant role in, the final stage of the professionalization of institutions of higher education in general. It was at just this time that such institutions - at first primarily elite universities and colleges, but soon schools of all types - began requiring faculty in the humanities and the social sciences to produce well-received monographs (or, in some cases, a number of journal articles) to qualify for tenure and promotion (accreditation). Superior teaching, institutional service, and professional reputation were no longer sufficient for moving into and up the faculty ranks: quality and quantity of publication became an additional and, soon, the primary, qualification for faculty appointment and hierarchical elevation. If administrations were to require published books as a major part of a decision on faculty tenure or promotion, then it was necessary 
for the books to arrive at that decision point already professionally authorized. University press editors were rarely adequately qualified to perform this function, so monographs needed the endorsement of credentialed external reviewers to serve in this role.

The mutually reinforcing, symbiotic, professionalization of the university and professionalization of the presses acted as a further control mechanism on the system of scholarly communication. The idea of applying scholarly standards to monographs was not an innovation, of course: many press editors and many post-publication reviewers had long invoked them on a somewhat haphazard basis. What changed were the uniformity, rigor, and consistency of the application of such standards - and the immediate and significant negative consequences of failure to conform (the negative feedback loop). Postpublication administration accreditation, when layered upon the pre-publication peer review, authorization, provided strong likelihood that monographs published within the university press system could be relied upon to meet at least a minimum scholarly standard. Manuscripts that failed to achieve such authorization would (in principle, at least) not be published; faculty who produced an insufficient number of vetted publications would (again, in principle) not be retained or promoted (accredited).

Several anomalies in the resulting system are worth mentioning.

By the end of the 1960s, there were approximately 50 university presses (many quite small) (Givler, 2002), although many more institutions of higher learning - certainly several hundred - were then requiring published monographs in many fields. Currently there are approximately 100 university presses in the US and, while not all of the 2000 institutions of higher learning in the country require published books on the part of their humanities and some social science faculties, a significant majority certainly does, implying that 100 presses and their home institutions are in fact subsidizing at least 1000 other universities and colleges who are free riders on a system that they rely on but do not support (Greenstein, 2010).

The preceding discussion also makes clear that while university presses are oriented to their home administration for material and other support, their published faculty authors are situated in a far wider swath of institutions of higher learning, and these authors are far more concerned with own administrations (and their power to reward or punish). This creates a disconnect between the limited number of administrations that support a university press and the much larger pool that knows little about university presses and publishing, yet require their products for status decisions regarding their own faculty. The result of this disconnect is not merely financial inequity but the reduced likelihood of rational information and observation about, much less remediation of, the scholarly publishing system as a whole.

University presses have always made independent decisions about which scholarly areas to publish (much less which books to publish), decisions that have been based on press history (sometimes just plain inertia), press resources, university strengths, product marketability, editorial and marketing preferences and idiosyncrasies, and other factors, both rational and irrational. Presses have never collaborated to efficiently allocate publishing areas in order to ensure complete or optimal distributed coverage of fields. In the diagrammed publishing system presented in Figure 2, it is only after publication, when books get to the library distributors who sell books by categories to academic libraries, that books from all academic publishers are even sorted and aggregated by field. 


\section{The "Analogue" System of Print Scholarly Publishing}

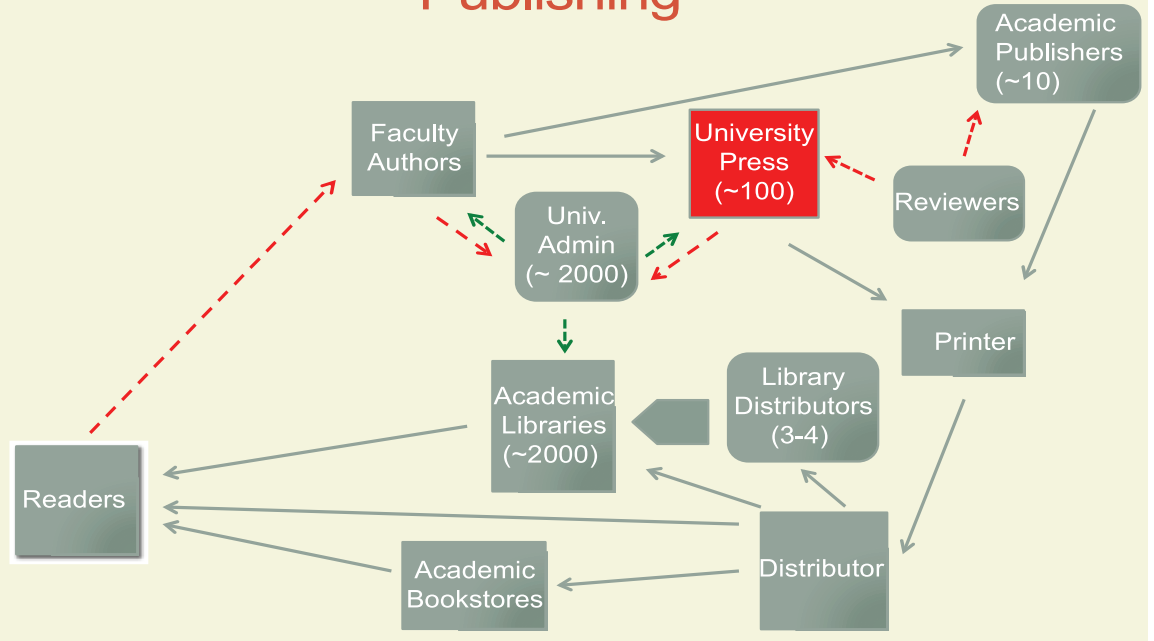

Figure 2. The 'analogue' system of print monograph scholarly publishing.

The system of scholarly publishing in the above figure embeds the feedback mechanisms (authorization and accreditation) inside the system, because these are not externalities or options, but are fundamental to system identity and maintenance. (A third control mechanism or mode of authorization - post-publication reviews in professional journals - is implicitly contained in the 'reader' venue of the diagram.)

The scholarly print publishing system itself proved stable or at least sustainable (relatively if not rigidly homeostatic) for a half-century. The sites depicted increased or decreased in their quantity (for example, the number of university presses increased by only 15 from 1970 to 2000) (Givler, 2002), but remained unchanged in their nature and function. The vector of the circuitous flow from manuscript to printed books to readers was invariant (although, to the dismay of presses, books sold per title declined continuously).

In short, the analogue scholarly publishing system - engaged in the production of books that are bounded (literally, bound), identifiable (clearly and immutably authored and titled), and stable (the container and the content of each book remained fixed) - is itself stable, bounded, continuous, well ordered, and well policed.

As in the Darnton model, the system as depicted in Figure 2 remains open to environmental influences, in particular, the states of the local and national economy and external revenue flows. In addition to revenue from book sales and university subventions that are internal to the system as depicted, a major factor supporting the coalescence of the system of scholarly publishing in the 1960s was the vast amount of federal funds that flowed into universities as a whole, and into the scholarly publishing system, directly and indirectly, through libraries and presses. Post-Sputnik, the government was determined to accelerate 
development of US research capabilities (infrastructure) as well as by direct funding of research activities, impulses that were strengthened by the outbreak of the Vietnam War. The National Science Foundation saw its budget increased from its 1950 founding level of US $\$ 15$ million to a post-Sputnik amount of US\$134 million in 1959 and nearly US\$600 million in 1968, and the Foundation lavishly supported a wide range of research projects and their subsequent publication throughout the 1960s (Mazuzan, 1994: ch. 3). The Defense Department, deeply enmeshed in the Vietnam War, funneled much funding into university research as well as into publications (Mazuzan, 1994: ch. 3). Significant publication subsidies also came, both overtly and covertly, from the CIA in this period of highintensity Cold War competition (Saunders, 1999: 244-247). Libraries, whose budgets expanded throughout the decade, were able to commit to substantial standing orders for almost all university press books. Presses inevitably assumed that the higher standards they had imposed on their monographs, and the increased professionalism of their operation, were responsible for their strong performance. No one had reason to imagine that this period of prosperity, and the stability it meant for libraries and presses, would prove extremely brief, or that the golden age for the analogue publishing system - and for higher education as a whole - would span only a decade.

\section{From abundance to scarcity}

As rapidly as the financial spigots were turned on in the 1960s, so were they precipitously reversed in the early 1970s (Mazuzan, 1994: ch. 4). The escalating costs of the Vietnam War (and the escalating public opposition to the war), as well as the public excitement and relief engendered by the US leapfrogging past the Soviet Union to the moon in 1969, reduced the federal government's felt urgency or capacity to fund universities as it had for the preceding decade. In particular, libraries were hit hard, and their reduced budgets resulted in a protracted decline of library orders to presses. Universities, now struggling with a suddenly underfunded research infrastructure, began reducing press subventions as part of much wider cuts (Givler, 2002). As the universities in a short time went from boom to bust, so inevitably went the presses.

The analogue system bent but did not break under a series of major financial blows in the 1970s. In addition to the decline in federal funding, the decade witnessed the following: a major stock market crash and global oil crisis in 1973; inflationary growth through the whole period; a major recession from1973 to 1975; another oil shock in1979; and record stagflation throughout the end of the decade (Samuelson, 2008: 259-266). Separately and together, these economic shocks took a significant toll on publishing revenues. At this time as well, large commercial publishing conglomerates (e.g. Springer, Bertelsmann, and Wiley) gained control over many or most of the most prestigious academic science, technology, and medicine (STM) journals (Carrigan, 1996; Thatcher, 2000), and compelled university libraries to pay relentlessly escalating and exorbitant subscription prices for articles based on research that was primarily funded by the US government, foundations, or by the universities themselves. In turn, academic libraries, already faced with static or declining budgets, were forced to assign much higher proportions of those beleaguered acquisitions budgets to these journal subscriptions, and reduce, by at least the same amount, their purchase of academic monographs. University 
presses, reeling under this simultaneous decline of multiple revenue streams, reacted by raising the price of their books - with the inevitable result that libraries reduced orders even further, and so the vicious spiral (downwards of sales, and upwards of prices), that would continue for the next 40 years, commenced.

These internal system changes and the changes in the system boundary conditions beginning in 1970 damaged the analogue publishing system severely, rendering homeostasis (Wiener, 1948 and 1961: 114-115) - at either the system level or at the level of individual publishers - increasingly problematic. The print-based analogue system was so weakened as a result, and had so little margin to maneuver, that when subjected to the full force of the digital assault 30 years later, it could provide only token resistance.

\section{The digital Trojan horse: Sustaining innovation}

Under increasing stress for a decade, in the 1980s scholarly publishers, as did all other businesses, rapidly and enthusiastically incorporated in their daily operations the software programs that accompanied the widespread introduction of desktop computers (Freiberger and Swaine, 2000). Word processing programs - e.g. Word Star, WordPerfect, XyWrite, and the eventual champion from Microsoft, Word - were introduced in the late 1970s and early 1980s, and publishers immediately appreciated and appropriated their value for manuscript submission, editing, copyediting, and composition (Eisenberg, 1992; Thompson, 2005: 406-412). Powerful desktop spreadsheets and database programs became available in that period as well. VisiCalc, Lotus $1-2-3,{ }^{2}$ and then, of course, Microsoft's Excel permitted rapid calculations to be performed on massive amounts of financial or other quantitative data (Power, 2004); database management programs, such as $A B 2$, FoxBASE, Oracle, SQL server, and others, facilitated the storage, manipulation, and transmittal of large amounts of information within and between organizations.

These general digital tools significantly increased the productivity and efficiency of any kind of business and, in particular, served to protect the narrowing and endangered financial margins of publishers. In the 1990s a new class of software emerged that was publisher specific. These were the powerful page design tools that relieved the production departments of the necessity to lay out every page of a manuscript by hand (both in the initial layout, and then yet again whenever changes were made to the text or to the number and size of illustrations). Beginning with Aldus PageMaker 1.0 in 1985, and continuing through Adobe PageMaker (1994), QuarkXPress (1992), and Adobe InDesign, 1999 (Adams, 2008), this software permitted text to flow freely into pages of defined dimensions, and to flow automatically around illustrations and around insertions and deletions in the text. The productivity savings for publishers was substantial and invaluable. In terms of Clayton Christensen's conceptual framework, digital technology acted at first as a sustaining innovation (Christensen, 1997: xviii), propping up the existing publishing system, without threatening existing markets or recruiting new ones.

\section{Digital becomes disruptive}

However, these digital accessories were only short-term palliatives: the analogue publishing system was already on a fatal slide, while the growing potency of digital tools, 
and the ever-increasing publishing options made available through digital means and channels, began suggesting the possibility, indeed the inevitability, of a complete role reversal, resulting in a scholarly publishing system in which the scholarly content is overwhelmingly born-digital, then digitally organized, digitally processed, digitally produced, and digitally disseminated (and in which print versions would play, at best, only a supplementary or niche role). Digital technology changed, in the course of only two decades, from a sustaining innovation within the scholarly publishing circuit to a disruptive innovation (Christensen, 1997: xvii; Christensen and Raynor, 2003: 32-51); from increasing productivity while supporting the traditional values and markets within the legacy print publishing system to an innovation that first suggested, then insisted on, a radically transformed system of scholarly publication, one premised on digitally inspired and digitally mediated resources and perspectives introduced at every juncture of the system, as well as throughout all system flows and outputs.

An unordered and incomplete list of (and comments about) some of the most relevant digital affordances that contributed to this system change includes at least the following.

- The powerful search and discovery tools that digital publication makes possible have done much to accelerate the migration of scholarly publishing from printbased dominance to digital primacy.

- Probably too much has been made of the digital capacity to enhance books with audio and visual components. Even should this not prove the norm for most digital books, still these options will prove beneficial for many projects, and will create whole classes of publication in which print-only content, if it exists at all, will be considered a diminished or even impoverished version of the book. Vectors: Journal of Culture and Technology in a Dynamic Vernacular ${ }^{3}$ and Kairos: A Journal of Rhetoric, Technology, and Pedagogy ${ }^{4}$ are each born-digital, peer-reviewed, multi-media journals that publish major scholarly articles that could be presented in no other format.

- Permitting the content, not the traditional print containers, to dictate publication length and format. ${ }^{5}$ In the print system, formats can only be chosen from the familiar binary choices: on the one hand, articles (generally of lengths less than 30 pages), aggregated into issues of scholarly journals and sold via a subscription model; on the other, monographs, almost always of lengths greater than 100 and less than 400 or so pages. The exclusivity of those two physical containers was and is entirely determined by the economics, the exchange-value, required by publishers, and not in order to optimize the use-value, for either authors or readers, of an intellectual or scholarly argument or project (Esposito and Pochoda, 2011). In the Procrustean print system, authors are compelled to fit their argument into the short-form article or the long-form text (itself falling within a limited spectrum of potential lengths). By contrast, the digital regime, in principle, permits publication in any length and in a wide and expanding variety of digital (as well as print) containers.

- The opportunity, which in many fields of research is becoming the necessity, for generating, curating, archiving, sharing, and disseminating very large and mutating data sets (Borgman, 2007: 115-149, 2011). Digital publishing is obviously the 
only format of choice for such projects (and raises many thorny issues of authorization and accreditation).

- Although the first digital copy may not be inexpensive, the marginal cost of additional copies, whether it is one or one million, is essentially zero. So wide digital dissemination is not limited, in principle, by cost, but only by discoverability, Internet access, and reader interest. Negligible marginal cost also encourages open access $(\mathrm{OA})$ perspectives and implementation, since the cost is bounded whatever the extent of distribution.

- Web 1.0 makes possible direct and immediate linkages to full-text versions of many of the citations, footnoted sources, and bibliography mentioned in the text, providing considerable assistance to readers.

- Web 2.0 features a vast range of web-mediated pre-publication and post-publication interactions among the authors, readers, commentators, and editors (as well as interactions between books and other books) (Esposito, 2003; O'Reilly, 2005). Scholarly books in such a rich digital publishing ecosystem not only benefit from but may be premised upon community engagement throughout the publishing system, and the books themselves become the catalyst for the coalescence of such communities on either a transitory or more permanent basis (Nash, 2010).

- Web 3.0, the semantic web, permits fine-grained algorithmic tracking and data mining of many of the endless uses and interactions, connections and disconnections obtaining among humans and a myriad of digital products. It maps, for the first time, the complex real-time patterns, rhythms and intensity of actual usage, assesses demographic differences, and minutely tracks the digital interactions between books, readers, authors, and publishers (Antoniou and Van Harmelen, 2008). Thereby extensively informed about reading practices and interactions within the publishing system, we can become better publishers.

- Many flavors of do-it-yourself web-based publishing in the scholarly sector (as elsewhere) have already emerged, including academic wikis, blogs, file-sharing applications, listservs, Facebook and other social media sites, Twitter streams, and much else. Currently, such distributed publishing is neither authorized nor accredited in the scholarly system, but challenges to the orthodoxy are beginning to appear from within the scholarly disciplines themselves and from scattered but influential individual faculty members protesting the inflexible application of rigid inherited standards and norms to determine what is a legitimate scholarly contribution in the digital era (Cohen, 2008, 2010; Fitzpatrick 2011).

At first, such publications appeal to a limited niche of academic writers and readers: because they have not cleared the accreditation hurdle, they qualify as Christensen's low-end disruptions (Christensen, 1997: 46, 63, 212; Christensen and Raynor, 2003: 45, 46), unable to provide some of the primary rewards attached to academic publication. However, as standards of accreditation become more flexible and diverse (which should not be interpreted as the end or even the diminution of scholarly or intellectual standards), these low-end disruptors and disruptions will likely migrate upwards in professional and administrative esteem, taking a place alongside the traditional scholarly productions of university and scholarly presses. 
Whether or when administrations will accredit any versions or aspects of such publishing remains problematic, but as non-traditional and flexible digital publishing forms and formats become increasingly common, the pressure for concomitant flexibility and pluralism in the associated areas of authorization and accreditation will likely prove irresistible as well. Alternative or supplementary forms of authorization, for example public crowd-sourced post-publication assessments, will undoubtedly acquire some degree of academic legitimacy if accompanied by sufficient controls and annotation, and if they are appropriately positioned along a gradient in scholarly import (Acord and Harley, 2012).

\section{Gearing up digitally}

As rapidly as their resources permit, university presses large and small are now digitizing all phases of their operations and installing digital workflow tools, beginning with the ingestion of manuscripts (themselves digitally formatted by authors so that they engage almost seamlessly with the subsequent publishing stages) on through editing, production, and dissemination in a variety of digital formats and digital channels (Thompson, 2005: 312-318). Extensible markup language (XML) processing of manuscripts has been pushed ever further up toward the commencement of the publishing process, thereby readying an accepted manuscript for prompt, simultaneous print and digital production. Those production processes themselves have been heavily digitized, and are often organized through use of powerful digital production platforms that are efficient and versatile. Publishers make use of an increasing array of digital tools to create and disseminate rich metadata; to archive, search, and retrieve content of many kinds; to handle contracts, permissions, rights, and royalties; and to track multiple and complicated workflows throughout all press departments and stages (O’Leary, 2011b).

Currently, a confusing and inefficient array of digital formats emerges from this processing: PDFs for web use; mobipocket (for Amazon); apk (for Android); Daisy (for vision impaired); and epub and epub3 for almost everyone one else. Reflecting an immature industry, channels for digital dissemination are equally diverse and dizzying: through direct to consumer commercial sites (e.g. Amazon, Apple, Barnes \& Noble); through commercial eBook distributors selling to an array of 'e-tailers' (e.g. Ingram's CoreSource, Perseus's Millennium project); through commercial aggregators selling largely to university and public libraries (e.g. ebrary, netLibrary, OverDrive, MyiLibrary); through university press-affiliated aggregators (Project MUSE/UPCC, University Press Scholarship Online, Books at JSTOR), as well as directly though individual press web sites to consumers.

Similar chaos prevails throughout scholarly publishing. For example, the largest scholarly and scientific presses in the US and Europe have leveraged their considerable scale to create impressive aggregated digital packages consisting either exclusively of their own titles or with supplementation from smaller academic presses (Kelley 2012). Unfortunately for users, each comes tethered to its own incompatible or digital rights management (DRM) protected proprietary platform. 


\section{The digital soup}

However, for all of this churning, experimenting, and expanding digital activity, nothing resembling a viable long-form digital scholarly publishing system exploiting the full potential of digital scholarship and digital dissemination has yet coalesced or even dimly revealed its initial configuration. By analogy with the biological 'soup' that is posited as the incubator of organic life on earth, we have now what resembles a primordial digital scholarly publishing soup - very much on the boil as digital 'atoms,' digital affordances, are produced and added at dizzying rates, and digital venues, digital resources, digital workflow tools, digital archives, digital platforms, and digital receptors are connected, combined, and aggregated on the fly into digital 'molecules,' while previous attempts at molecular combination and control are already disintegrating.

Too little productive or persuasive thought has been given to what the fully digital scholarly system will or should look like; how it will be assembled, coordinated, and networked; what venues inside and outside the university will participate and in what roles; and what will be the underlying foundation, the digital support system or cyberinfrastructure (an integrated suite of digital hardware and software platforms; data storage, retrieval, and sharing sites and channels; and digital social practices and services that will best facilitate collaborative intra-university and inter-university scholarly digital publishing) (Atkins et al., 2003). A higher digital life form, a digital system, cannot emerge from the bubbling digital soup until we have far more developed versions of both a robust digital substructure (in part, the cyberinfrastructure just discussed) and an equally vital digital superstructure (consisting, in part, of born-digital or born-again digital scholars and scholarship, each deeply embedded in digital processes and digital resources).

\section{The epistemic break}

Even now, however, before more than the most preliminary digital forays are visible, it should be clear that a digital publishing system - either in form or in content; in the containers or the contained; in forms of scholarship or formats of scholarship - will not be simply the print system in digital dress. What is underway is not just a change in formats and publication processes, but a much more fundamental, ontological, change in what it means to be a participant in a digital as opposed to an analogue system, or, in particular, in a digital scholarly publishing system as opposed to the legacy print system.

One elementary clue as to the profundity of this imminent epistemological break is the common observation that roles in digital publishing are already becoming fluid, mutable, and multiple, and that this shape shifting, this newfound disdain for fixed publishing roles, identities, or boundaries, is inherent in the digital system. This is already visible in the trade publishing world where variations of publishing alchemy are displayed on almost a daily basis. Before our eyes, publishing roles that have been stable and separate for centuries are suddenly becoming volatile and interchangeable: overnight, authors become publishers and/or distributors; distributors become publishers and literary agents; literary agents become publishers; readers become critics and authors. No traditional publishing role, much less traditional publishing entity, seems 
stable or settled in the fully digital publishing universe: the digital system, by its nature, empowers its components to shed rigid identities and labels and be not a this or a that but both, and more, simultaneously and sequentially. ${ }^{6}$

Whereas the analogue system is, in principle at least, deterministic (since the state of each system component can be specified at a given time), the illustration above suggests that the digital system as a whole, as well as in its parts, is stochastic, amenable to specification only within a range of probability at any time.

Despite the danger in pressing analogies or metaphors too far (as regards to content areas that are far afield), it is tempting to characterize the analogue print scholarly publishing system as Newtonian in nature, composed of stable, identifiable, inertial units whether they be planets, apples, and atoms, or authors, publishers, and bookstores - that interact in regular fashion according to known or discoverable but immutable laws or regularities. In contrast, the digital system is best likened to a quantum system, composed of units, or packets of units, that can be alternate things simultaneously, as an electron or light itself is, in the quantum reckoning, both a particle and a wave. ${ }^{7}$ More importantly, the antipathy of the digital system to imposed or inherited limits, its corrosive effect upon artificial or historical boundaries to textual production and consumption, may not be coincidental or contingent but a consequence of its essential nature.

In contrast to the analogue publishing system, in which the relationships among the components tend to be linear and limited, the pattern, the solution set, manifested by any 'digital' system is not necessarily obvious or easily characterized. The analogue system is relatively static in its components and in its connections, while the digital circuit is in flux in multiple dimensions. It is intrinsically a network of shifting connections, a set of shifting sets, a community of shifting communities.

\section{Publishing shrews and dinosaurs}

The real dinosaurs suffered evolutionary defeat by shrew-like mammals, in part because their massiveness, their inertia in the face of major environmental trauma, proved to be a fatal liability (Dawkins, 2005: 169-173). However, the slow biological evolutionary analogy breaks down here, since first-generation publishing shrews can mutate astonishingly rapidly into publishing giants: Amazon, Google, and Apple, currently publishing's Big Three dinosaurs, all began as publishing shrews just a few years ago. Further, the still flourishing commercial STM dinosaurs have demonstrated how agile they can be not only in creating powerful new digital resources and platforms, but also in almost effortlessly mimicking the shrews by appropriating, for their own benefit, digital developments such as OA that were, in part, designed and promoted to undercut dinosaur domination of the academic marketplace. ${ }^{8}$ University presses and/or the publishing-inclined university libraries, will, of course, try to protect and expand their home terrain by claiming the disruptive digital technologies and the emerging scholarly digital publishing system for themselves, but whether they have the imagination and the resources to effect and enforce such shrew-like aspirations remains to be seen (Pochoda, 2010b).

Major challenges to the publishing dinosaurs - university dinosaurs as well as trade dinosaurs -- will likely arise not from the center of their respective ecosystems but from the periphery. ${ }^{9}$ Digital shrews, bonding almost genetically to all the free or inexpensive 
digital publishing-ware that is fast becoming available, and having no emotional or financial bondage to the analogue print system, may find a way to insert themselves into the digital scholarly system by their born-digital ability to truly 'float like a butterfly, sting like a bee' in the mutating digital atmosphere and ambience.

\section{Some recommendations moving forward}

Because so much hinges on it, and so much pressure is behind it, that there will be an organized digital scholarly publishing system for monographs as well as for journal articles, different in kind from their print predecessors, is a certainty - although when and even where, much less how, they will coalesce is entirely and predictably obscure as yet. Nor, if my arguments or inferences about the nature of the long-form digital system are plausible, will coalescence occur in the manner or in the venues to which we have become accustomed. Universities may or may not decide to claim the transformed scholarly publishing system for their own - although I believe that it will be seriously detrimental to scholarship if they do not - but if they do it will be because, at least in part, they appreciate that the publication of knowledge in the digital era will be seamlessly intertwined from the outset with the production of knowledge. That will require major reconsideration of the vexed decisions regarding what level and what kinds of support are necessary to ensure that fundamental university principles of maximizing scholarly production and dissemination are fully realized. While it may be too early to delineate the specifics of the scholarly digital publishing landscape going forward, it seems possible to infer some of its broadest outlines.

If anything seems a key to digital scholarly publishing it will be the pervasive active and interactive involvement of diverse scholarly communities, supplementing if not entirely displacing the traditional inflexible, hierarchical systems of authority, authorization, and accreditation. There is both a specific and a general justification for this assertion. The specific argument hinges on the wide distribution of skills and interests relevant to digital publication throughout the university community, and on the imaginative and disruptive role of smaller, sometimes ephemeral, intra-university communities and individuals in vigorously adopting (or even generating) the many digital publishing affordances that are neither part of legacy publishing practices nor have yet been legitimated by the traditional mechanisms of assessing and rewarding faculty achievement. The general argument - as has been strikingly developed by writers such as David Weinberger (Weinberger, 2011), Clay Shirky (Shirky, 2008), and Jonathan Zittrain (Zittrain, 2008) - is that in the digital era the crowd is smarter and much more efficient than any of its individual members, or, as Weinberger memorably puts it, the smartest person in the room is the room.

War, we have been told, is too important to be left to the generals, and as publishing decisions become ever more explicitly engaged with foundational university values, as well as with the digitally oriented scholarship emerging from a wide array of formal and informal university venues, academic publishing in the digital era will be deemed too important to be left to publishers and to uncontrolled market determinations of publishing value. For example, although I believe that there will be a continued need, at least selectively, for dedicated, professional editors operating within university press venues, committed to discovery, recruitment, selection, assessment, remediation, and 
enhancement of long-form scholarly projects, presses will have to share their inherited academic publishing monopoly with many other university venues and with shifting communities of scholars interacting and publishing through the web.

The expanding range of authorized publications - from formally reviewed projects of widely varying lengths, including vast collectively created and shared datasets and databases, to an increasingly dizzying array of less formal scholarly exchanges - will make the task of locating, sorting, curating, archiving, storing, preserving, and displaying such heterogeneous scholarly productions a task that only academic libraries are experienced and dedicated enough to assume. ${ }^{10}$ (However, there is no persuasive theoretical or practical rationale for placing imperialistic academic libraries in charge of these emerging campus-wide digital publishing collaborations.)

University IT divisions, working closely with the traditional library and press venues, and collaborating, as well, with schools of engineering and computer science, will be crucial in helping create and install the evolving cyberinfrastructure at a campus and inter-campus level (Pochoda, 2008). Digitally invested and digitally savvy faculty from an extraordinary wide range of digital humanities, digital design, and digital performance centers, and a broad spectrum of academic departments, will also be a central part of this collaborative digital publishing effort.

The coordination of these elements on a single campus will be immensely complicated, given the range and diversity of the groups and projects involved: how that collaboration is effected, marrying the centralization required for efficiency with the decentralization necessary to incorporate both formal and informal campus venues, will likely be settled differently by each institution. The university itself, through its administration, will have to be involved, directly or indirectly, to coordinate and fund these distributed campus publishing entities; to provide appropriate accreditation and support for the many emerging forms of digital publication; and, in general, to ensure that the basic university commitment to optimizing the production and dissemination of scholarly materials receives priority over the narrow self-interest of any of the individual publishing venues. ${ }^{11,12}$ What should emerge on each campus is a distinct, heterogeneous publishing ecosystem (itself a participant in a complex national and international publishing network) whose very diversity and permeability ensure a powerful, evolving institutional publishing identity. ${ }^{13}$

Scale has always mattered in publishing, and scale in digital publishing is no exception. Leveraging publishing assets across a campus will produce significant and muchneeded economies along with superior performance. This is true whether or not the business model adopted is, as at present, in a large part market driven or, more likely, and much more desirably, tipping towards an OA hybrid model, in which the preponderance of publishing expenses are supplied by the home institution or foundation grants, but with ancillary revenue derived through sales of specialized digital formats, print on demand, and other associated publishing activities. ${ }^{14}$

The core university commitments to the freest and widest distribution of research, combined with zero marginal cost for digital distribution, makes a compelling case for an OA university scholarly publishing model - for monographs as well as journals. ${ }^{15}$ However, such a normative perspective not only begs the question of how the substantial operating costs for digital monograph publication will be paid, but also, as Donald Waters demonstrates (Waters, 2008), it evades the necessary concern for important issues such 
as the sustainability of the digital business model and of support for continued innovation in scholarly publishing.

Reinventing each of the digital affordances, the circuitry, and the cyberinfrastructure on each campus obviously would be inefficient. Powerful digital platforms (at least capable of performing labor-intensive production and copyediting tasks, but also able to provide aggregated marketing and sales support), should be shared by many, perhaps all, colleges and universities. Such coordination will, at the least, require organization that accommodates the diversity and complexity of the array of participating university publishing communities, while helping effect a system-wide coherence and efficiency. Further, only by involving not just hundreds but thousands of institutions of higher education in the planning and the maintenance of publishing activities will costs be equitably allocated, distributed asset use optimized, and an intricate array of publishing needs met (Pochoda, 2010a). This explicit, organized, inter-university collaboration represents yet another required level of the impending scholarly publishing ecosystem, encompassing all the others, and itself confronted with the pervasive issue of maintaining system-wide coherence while supporting the rambunctiousness of campus-based publishing units nationwide.

The magnitude and the complexity of organizing the digital scholarly publishing system should be neither surprising nor disturbing but refreshing. The digital system, which will be part of the single biggest disruption in scholarly, much less human, communication since at least Gutenberg, 450 years ago, will bring with it fundamental (and many unforeseen and unforeseeable) transformations not only in how and where scholars communicate what they know, but also in what they know, in how they know, and in the ways in which they know. These profound changes awaiting scholarly publishing in the digital era will be an integral part of the much larger digitally driven epistemic transformations of scholarship, of scholarly discourse, and of the academy in general. ${ }^{16}$ In the language of seismologists, this is truly 'the big one'.

\section{Acknowledgments}

I would like to acknowledge the unusual assistance of Nicholas Jankowski who solicited, accommodated, edited, and much improved this essay. He was an invaluable editor, particularly for this piece that, with its personal focus and speculative nature, deviates from the style and methodology of most New Media \& Society articles.

\section{Funding}

This research received no specific grant from any funding agency in the public, commercial, or not-for-profit sectors.

\section{Notes}

1. The observations on publishing throughout this essay are based on the cited sources and on many more uncited sources, but rely especially on my more than 30 years of hands-on publishing experience, both in the trade book world (as editorial director of Anchor Books and Dial Press at Doubleday and publisher of Prentice-Hall Press at Simon \& Schuster) as well as in the university press world (as associate director and editor-in-chief at the University Press of New England, and for a decade, until my recent retirement, as director of the University of Michigan Press). UMP received much attention for being in the forefront of the university 
press transition from print to digital publishing, for its selective commitment to Open Access monograph publishing, and for close collaboration with the University Library in its publishing activities.

2. Douglas Carlston has some revealing stories about the creation of WordStar, VisiCalc, and Lotus 1-2-3 (Carlston, 1985: 38-40, 120-123, 195-196).

3. http://vectors.usc.edu/journal/index.php?page=Introduction.

4. http://www.technorhetoric.net/about.html.

5. Brian O'Leary (O'Leary, 2011a) provides a superb discussion of the ways in which digital publication permit context and content, and not the 'container' in which content is embedded, to determine published form and format.

6. The academic scholarly world is, in principle, much more prepared for some of its leading actors to assume alternate publishing roles, both simultaneously and sequentially, than is the trade book publishing sector. In the scholarly print publishing system, the same faculty member is frequently a monograph author, an external reviewer for one or more presses, a reader of many academic monographs, and a reviewer for scholarly journals. Such versatility is relatively widespread among academics, and should certainly abet the scholarly digital transition that facilitates role switching in principle.

7. The state of an electron or system of electrons in quantum mechanics can only be presented in terms of probabilities, that is, stochastically, and so bears at least a remote correspondence to the digital model as presented above.

8. John Seely Brown and Paul Duguid go even further, and argue that in this stage of the information society, it will be the large organizations, able to command large networks, rather than the fabled garage start-ups, that will be the source of major innovation (Brown and Duguid, 2002: 26).

9. An interesting recent edition of the Scholarly Kitchen blog is devoted to a discussion among its principle contributors of just this issue. 'Ask the Chefs: "Who Will Win the Future - The Small, the Mid-sized, or the Big Organization?”' (Scholarly Kitchen, 2011).

10. In a very recently published article (that I read only as this essay was about to be published), Richard Lorimer endorses much the same scenario as presented here for the relationship between university presses and academic libraries in the digital publishing era (Lorimer, 2012). I agree with almost all of the points made in this insightful article.

11. In a very important and much discussed report, "University Publishing in the Digital Age," done for the Ithaka Group, the authors, Laura Brown, Rebecca Griffiths and Matthew Rascoff, strongly urge university administrations to play a very active role in scholarly publishing in the digital age (Brown et al, 2007).

12. Eleven provosts of mid-western research universities, all members of the Committee on Institutional Cooperation (CIC), recently issued an enlightened statement along these lines. The provosts were expressing their support for the proposed Federal Research Public Access Act (FRPAA) that would mandate OA status after a six-month embargo period for all published articles that had received federal funding support. However, in addition, the provosts strongly endorsed some broad publication principles to guide their university presses: in particular, 'Ensuring that our own university presses and scholarly societies are creating models of scholarly publishing that unequivocally serve the research and educational goals of our communities, and/or the social goals of our communities.' In addition, the provosts' statement supported OA institutional repositories on each campus, and further addressed the developing faculty accreditation issue, in favor of 'ensuring that promotion and tenure review are flexible enough to recognize and reward new modes of communicating research outcomes.' (11 Research University Provosts, 2012).

It is noteworthy that the professional association of university presses, the Association of American University Presses (AAUP), issued a statement opposing the FRPAA, providing 
another clear demonstration of how university values and university press values - at least as communicated by the AAUP - have significantly diverged in recent years.

13. Clifford Lynch, the Director of the Coalition for Networked Information, has proposed a 'future system of many distributed university presses mainly focused on the editorial production of scholarly monographs, supported by a very small number of digital platforms for managing and delivering these monographs as a database rather than transactionally to academic and research libraries' (Lynch, 2010).

14. Several academic presses - including National Academies Press, University of Michigan Press, Penn State University Press - have, in all or in part of their publishing program, distributed the digital version of monographs free over the web while continuing to charge for the print (or print-on-demand) version and, in some cases, for non-PDF digital versions of the title. Although it is not entirely clear whether or not the free digital distribution cannibalizes print sales, given the relentless and accelerating decline of print sales overall, this approach can at best be of short-term assistance to financially stressed presses.

15. John Willinsky's important book (Willinsky, 2006), though dealing exclusively with journal publishing, makes a powerful case for open access scholarly publishing in general.

16. David Weinberger provides a compelling perspective on this epistemic shift (Weinberger, 2011).

\section{References}

11 Research University Provosts (2012) Values and scholarship. Inside Higher Ed, 23 February. Available at: http://www.insidehighered.com/views/2012/02/23/essay-open-access-scholarship (accessed 13 March 2012).

Acord SK and Harley D (2012) Credit, time, and personality. New Media \& Society.

Adams P (2008) PageMaker past, present and future. Available at: http://www.makingpages.org/ pagemaker/history/ (accessed 4 December 2011).

Antoniou G and Van Harmelen F (2008) A Semantic Web Primer. 2nd ed. Cambridge, MA: The MIT Press.

Atkins D, Droegenmeier KK, Feldman SI, et al. (2003) Revolutionizing science and engineering through cyberinfrastructure. Report of the National Science Foundation BlueRibbon Advisory Panel on Cyberinfrastructure. Available at: http://www.nsf.gov/od/oci/ reports/atkins.pdf (accessed 10 November 2011).

Borgman CL (2007) Scholarship in the Digital Age: Information, Infrastructure, and the Internet. Cambridge, MA: The MIT Press.

Borgman CL (2011) The conundrum of sharing research data. Journal of the American Society for Information Science and Technology. Available at: http://papers.ssrn.com/sol3/papers. cfm?abstract_id=1869155 (accessed 10 November 2011).

Brown JS and Duguid P (2002) The Social Life of Information. Boston, MA: Harvard Business School Press.

Brown L, Griffiths R and Rascoff M (2007) University Publishing in a Digital Age. Journal of Electronic Publishing 10(3). Available at: http://quod.lib.umich.edu/j/jep/3336451.0010.301? rgn=main;view=fulltext (accessed 10 November 2011).

Carlston DG (1985) Software People. New York: Simon \& Schuster, Inc.

Carrigan D (1996) Commercial journal publishers and university libraries: retrospect and prospect. Journal of Scholarly Publishing 27(4): 208-221.

Christensen C (1997) The Innovator's Dilemma: When New Technologies Cause Great Firms to Fail. Cambridge, MA: The Harvard Business School Press.

Christensen C and Raynor ME (2003) The Innovator's Solution: Creating and Sustaining Successful Growth. Cambridge, MA: The Harvard Business School Press. 
Cohen D (2008) Making digital scholarship count. In: Dan Cohen's Blog: edwired.org. Available at: http://edwired.org/2008/06/13/making-digital-scholarship-count/ (accessed 10 November 2011).

Cohen D (2010) Open access publishing and scholarly values. In: Dan Cohen's blog. Available at: www.dancohen.org (accessed 27 May 2010); http://www.dancohen.org/2010/05/27/openaccess-publishing-and-scholarly-values/ (accessed 10 November 2011).

Darnton R (1982/2009) What is the history of books? In: Darnton R (ed.) The Case for Books. New York: Public Affairs, pp. 175-206.

Dawkins R (2005) The Ancestor's Tale: A Pilgrimage to the Dawn of Evolution. Boston, MA: Houghton Mifflin Company.

Eisenberg D (1992) Word processing (history of). In: Encyclopedia of Library and Information Science, vol. 49. New York: Dekker. Available at: http://tinyurl.com/7p8f47e (accessed 4 December 2011).

Esposito JJ (2003) The processed book. First Monday 8(3-3). Available at: http://firstmonday. org/htbin/cgiwrap/bin/ojs/index.php/fm/article/view/1038/959 (accessed 10 November 2011).

Esposito JJ and Pochoda P (2011) Publishing through the wormhole: a new format for the borndigital publisher. The Scholarly Kitchen, 26 April. Available at: http://scholarlykitchen.sspnet. org/2011/04/26/publishing-through-the-wormhole-a-new-format-for-the-born-digital-publisher/ (accessed 10 November 2011).

Fitzpatrick K (2011) Planned Obsolescence: Publishing, Technology, and the Future of the Academy. New York: New York University Press.

Freiberger P and Swaine M (2000) Fire in the Valley: The Making of the Personal Computer. New York: McGraw-Hill.

Givler P (2002) University press publishing in the United States. AAUP Net. Available at: http://www.aaupnet.org/about-aaup/about-university-presses/history-of-university-presses (accessed 10 November 2011).

Greenstein D (2010) Next-generation university publishing: a perspective from California. Journal of Electronic Publishing 13(2). Available at: http://quod.lib.umich.edu/j/jep/3336451.0013.20 5?rgn=main; view=fulltext; $\mathrm{q} 1=$ pochoda (accessed 10 November 2011).

Kelley M (2010) A guide to publishers in the library eBook market. The Digital Shift. Available at: http://www.thedigitalshift.com/2012/02/ebooks/a-guide-to-publishers-in-the-library-ebookmarket/ (accessed 28 February 2012).

Lorimer R (2012) Libraries, Scholars, and Publishers in Digital Journal and Monograph Publishing. Scholarly and Research Communication 4(1):010136. Available at: http://www.src-online.ca/ index.php/src/article/view/43/117 (accessed 20 October 2012).

Lynch C (2010) Imagining a university press System to support scholarship in the digital age. Journal of Electronic Publishing 13(2). Available at: http://quod.lib.umich.edu/j/jep/3336451. 0013.207?rgn=main;view=fulltext;q1=Lynch (accessed 10 November 2011).

Mazuzan GT (1994) The National Science Foundation: a brief history. Available at: http://www. nsf.gov/about/history/nsf50/nsf8816.jsp (accessed 4 December 2011).

Nash RE (2010) Publishing 3.0. In: Speech at the BNG technology forum. Available at: http:// rnash.com/article/the-speech-chris-anderson-of-iwired-i-says-is-the-best-hes-ever-seen-onboo/ (accessed 10 November 2011).

O'Leary B (2011a) Context, not container. In: McGuire H and O'Leary B (eds) Book: A Futurist Manifesto. Sebastopol, CA: O'Reilly Media. Available at: http://book.pressbooks.com/chapter/ context-not-container (accessed 10 November 2011).

O'Leary B (2011b) Tools of the digital workflow. In: McGuire H and O'Leary B (eds) Book: A Futurist Manifesto. Sebastopol, CA: O'Reilly Media. Available at: http://book.pressbooks. com/chapter/tools-of-the-digital-workflow-brian-oleary (accessed 10 November 2011). 
O'Reilly T (2005) What is Web 2.0. O'Reilly Network. Available at: http://oreilly.com/web2/ archive/what-is-web-20.html (accessed: 10 November 2011).

Patten BC and Auble GT (1981) System theory of the ecological niche. American Naturalist 117(6): 893-922. Available at: http://www.jstor.org/stable/pdfplus/2460571 (accessed 29 February 2012).

Pochoda P (2008) Scholarly publication at the digital tipping point. Journal of Electronic Publishing 11(2). Available at: http://quod.lib.umich.edu/j/jep/3336451.0011.202?rgn=main ;view=fulltext;q1=pochoda (accessed 10 November 2011).

Pochoda P (2010a) Editor's note for reimagining the university press. Journal of Electronic Publishing 13(2). Available at: http://quod.lib.umich.edu/j/jep/3336451.0013.201? rgn=main ;view=fulltext;q1=pochoda (accessed 10 November 2011).

Pochoda P (2010b) UP 2.0: some theses on the future of academic publishing. Journal of Electronic Publishing 13(1). Available at: http://quod.lib.umich.edu/j/jep/3336451.0013.102?rgn=main; view=fulltext; 1 = pochoda (accessed 10 November 2011).

Power DJ (2004) A brief history of spreadsheets. In: DSSResources. COM version 3.6. Available at: http://dssresources.com/history/sshistory.html (accessed 4 December 2011).

Samuelson R (2008) The Great Inflation and its Aftermath: The Past and Future of American Affluence. New York: Random House.

Saunders FS (1999) The Cultural Cold War: The CIA and the World of Arts and Letters. New York: The New Press.

Scholarly Kitchen (2011) What's hot and cooking in scholarly publishing. Scholarly Kitchen, 7 November. Available at: http://scholarlykitchen.sspnet.org/2011/11/07/ask-the-chefs-who-willwin-the-future-the-small-the-mid-sized-or-the-big-organization/ (accessed 10 November 2011).

Shirky C (2008) Here Comes Everybody: The Power of Organizing without Organizations. New York: Penguin Books.

Thatcher S (2000) Fair use: the double-edged sword. Journal of Scholarly Publishing 32(1): 3-8.

Thompson JB (2005) Books in the Digital Age: The Transformation of Academic and Higher Education Publishing in Britain and the United States. Cambridge: Polity Press.

Waters D (2008) Open access publishing and the emerging infrastructure for 21 st-century scholarship. Journal of Electronic Publishing 11(1). Available at: http://quod.lib.umich.edu/j/jep/333 6451.0011.106?rgn=main;view=fulltext;q1=Waters (accessed 4 December 2011).

Weinberger D (2011) Too Big to Know: Rethinking Knowledge Now That the Facts Aren't the Facts, Experts Are Everywhere, and the Smartest Person in the Room Is the Room. New York: Basic Books.

Wiener N (1948 and 1961) Cybernetics: or Control and Communication in the Animal and the Machine. 2nd ed. Cambridge, MA: The MIT Press.

Willinsky J (2006) The access principle: The case for open access to research and scholarship. Cambridge, MA: MIT Press.

Zittrain J (2008) The Future of the Internet and How to Stop It. New Haven, CT: Yale University Press.

Phil Pochoda recently retired as director of the University of Michigan Press. Previously, he was associate director and editorial director of the University Press of New England; editorial director of Anchor Books and Dial Press at Doubleday; and Vice-President at Simon \& Schuster while publisher and editor-in-chief of Prentice-Hall Press. 